\title{
MANAGEMENT INFORMATION SYSTEMS: Managing the Digital Firm - 9th edition, authors: Keneth C. Laudon and Jane P. Laudon (Book Review)
}

\author{
Florin G. Filip
}

\author{
MANAGEMENT INFORMATION SYSTEMS: Managing the Digital Firm - 9th edition \\ Authors: Keneth C. Laudon and Jane P. Laudon \\ Pearson Prentice Hall, Pearson Education, Inc., Upper Saddle River, New Jersey 97458. \\ ISBN 0-13-153841-1; XXXII+641+22+14+2+21 pags.
}

This is the 9th edition of a successful textbook. The authors are two well-known and productive writers. K.C. Laudon, a professor of Information systems at Stern School of Business of the New York University, took his BA in Economics from Stanford and his Ph.D. from Columbia University. He is the author of twelve books and over forty articles about social, organizational and management impacts of information systems, privacy, ethics, and multimedia technology. Jane P. Laudon, a management consultant in information systems area, took her M.A. from Harvard University and her Ph.D. from Columbia University and authored seven books. Her main scientific interests are systems analysis, data management and software evaluation.

The background, scientific interests and expertise of the authors and their previous works had an obvious impact on the manner this book was conceived, written and accompanied by auxiliary materials (the CD ROM and companion web site).

The authors start from the premise that, nowadays, "Information systems knowledge is essential for creating successful, competitive firms, managing global corporations, adding business value and providing useful products and service to customers" (p. XIX). Moreover, they state that "in many industries survival and even existence without the extensive use of IT is inconceivable" (p.31). An important development the authors remark is the emergence of the digital firm, "where nearly all core business processes and relationship with customers, suppliers and employees are digitally enabled" (p.31).

In the book the management information systems (MIS) is defined at large as "the study of [computer based] information systems in business and management" (p.44). Besides, the authors adopt a broader view of information systems (IS) "which encompasses an understanding of the management and organizational dimensions as well as technical dimensions of the systems as information systems literacy" (p.20). Consequently, this book can be viewed as an effort made by the Laudons with a view to contributing to building up and consolidating such an information system literacy for current and future managers, which are to be confronted with several "major challenges concerning: a) "information system investments", b) "strategic business",, c) "globalization", d) "information infrastructure", and e) "ethics and security" (p.28).

The authors have noticed a "user - designer communication gap". In Table 15.3 (p.552) they give several examples of that gap. While the user is concerned with problem solving related questions such as: "Will the system deliver the information I need for my work?, "How quickly can I access the data?", ..., "How will the system fit into my daily business schedule?", the designer is preoccupied to find optimal answers to technology-oriented questions such as: "How many lines of program code will it take to perform this function?", ...,"What database management system should we use?

In order to help the future managers to successfully face the major challenges mentioned above and to solve the possible communication gap, the authors adopt a sociotechnical view and style of presentation. They combine technical aspects (drawn from computer science, management science, and operations 
research) with behavioral elements (drawn from economics, sociology, psychology). Throughout the book, the presentation method chosen contains, besides the introductimg MIS concepts, facts about realworld experiences (cca 200 examples are given), new technologies, and various exercises.

In accordance with the sociotechnical perspective adopted, the book is organized in four parts as it follows. Part One, which is made up of five chapters, addresses the organizational and managerial foundations of information systems. It introduces real-world systems and highlights their relationship with the organizations and managements. The concept of the digital firm is explained together with the fashionable concepts of e-business and e-commerce. Various types of information systems are reviewed (and they will be presented in detail in the remaining chapters). The four major business functions (sales and marketing, production and manufacturing, human resources and finance and accounting) are introduced with a view to being resorted to in an ending section of all remaining chapters. A special chapter is dedicated to ethical and social issues in the digital firm.

Part Two, which is made up of five chapters, addresses the various facets of the information technology infrastructure (ITI). ITI is viewed as a set of technology resources (hardware and software) and as a set of services (computing platform service, telecommunication service, data management service, application software service, IT management service, standards service, education and research and development service), composed both of human and technical capabilities (p.186). A particular emphasis is laid on describing the leading edge wireless technologies, and security and control aspects.

Part Three, which is made up of three chapters, describes several types of information systems. One by one, the main concepts of the Enterprise Applications (including enterprise [resource planning] - ERP, Customer Relationship Managing - CRM, and Supply Chain Management - SCM), knowledge management systems, and [group, and executive] decision support systems are presented.

Part Four, which is made up of three chapters, presents the process of building, implementing and managing the systems in organizations. Several important topics such as development approaches (based on lifecycle or prototyping), managing the necessary changes in the organizations, and various methods for evaluating the business value of the project are reviewed. The last chapter addresses the specific aspects of managing international information systems.

In comparison with previous editions, the present edition contains much up-to-date information about leading edge technologies. The chapters which address "wireless revolution", enterprise applications, knowledge management systems are new. Other chapters were re-written or/and completed with new topics.

Throughout the book, all chapters are organized in the same manner. Each chapter opens with the statement of five learning objectives. Then, five (in few cases, four) subchapters of text follow to provide the MIS concepts and real-world examples which are related to the learning objectives. Other common features to all chapters are: a) the opening case which describes a real world example and the coresponding diagram to analyze the case in terms of management, organization and technology model; b) the concluding section on management opportunities, challenges and solutions related to the theme of the chapter; c) the "Make IT your Business" section to place the concepts described in the chapter in relation with the major business functions; d) the "Chapter summary" organized in accordance with chapter objectives, e) the list of key terms, f) the review questions, g) the application software exercise to develop solutions to real-world business problems, $h$ ) the running case project (on a simulated firm entitled Dirt Bikes).

The book also contains an impressive List of references which is organized on chapters, a Glossary, three appendices of "hands-on" type (for analyzing a case study, designing a data base, and SQL), an Index of terms and an Index of organizations.

The text about information systems is supplemented by two IT - based learning aids: a) the companion web site (to guide the interactive study, to facilitate Internet connections, and to provide additional case studies), and b) the interactive multimedia CD-ROM (to be used either as an interactive study guide or as an alternative to the text). 
To conclude this review, I think this book, together with the CD-ROM and companion web site, is an excellent dynamic and active learning environment. I recommend it to be used as a textbook for the undergraduate students for information systems courses in business administration departments. It can also be utilized by the students in computer science as a complementary text, which can help them build a broader view on information systems.

Florin-Gheorghe Filip

Romanian Academy

125, Calea Victoriei 010071

Bucharest-1, Romania

E-mail: ffilip@acad.ro

Received: December 31, 2006 